\title{
Age influences on consumer behavior in the context of healthcare services: findings from Romania
}

\author{
Alexandru-Bogdan Ursoiu ${ }^{1}$ \\ The Bucharest University of Economic Studies, Romania ${ }^{1}$
}

\begin{abstract}
This paper presents some of the relevant elements that determine the specifics of consumer behavior related to healthcare. The role of age is analysed in relation to the importance of perceived quality factors for medical services, the favoured way of action should the need for healthcare re-emerge, the importance given to medics' names in regard to choosing a service provider, the hierarchy of the most important influencers on healthcare topics, the concern whether the made decision was the best or not. The primary data required for the analysis was provided by a direct quantitative research among Romanian patients. The findings regarding the influence of patients' age on some of the most important topics of consumer behavior are aiming to expand the marketing academic knowledge on the mechanisms that shape consumer behavior in the context of healthcare and also to support the service providers on adapting their business in order to deliver high benefits for the patients.
\end{abstract}

Keywords: Marketing, Consumer behavior, Healthcare services, Age influence

\section{INTRODUCTION}

The activities of goods consumption and services utilisation are varied and require certain levels of effort from the individuals [1]. Under the influence of consumer characteristics, the necessary decision-making regarding choice involves the workings of a series of variables residing in the psychic of the consumers, while the outcome is manifesting in the action performed as the result [2]. The providers, as supply-side participants to the market, find themselves on many occasions struggling to achieve adequate quality standards while being confined to budgetary limits [3], their capacity to develop being inevitably influenced by the reaction of the consumers. One of the most important challenges that the modern marketing must solve is finding the best ways to influence the behavior of consumers in order to purchase what the organisations are offering [4]. As indicated by [5], the attention of companies must focus on the process of consumer decision-making and the managerial competencies in that field must be continuously improved in order to succeed on the market.

Consumer age is a key demographic factor influencing behavior and purchasing decision-making mechanisms. It offers some of the most used consumer segmentation criteria, being relatively easy to measure [6] and providing valuable information on how consumers react to certain goods and services [7]. As show in [8], consumer demographics are among the most commonly used elements to achieve data disaggregation for analysis. The attractiveness of the market segmentation on demographic criteria is supported by the relatively easy character of correlation of consumer behavior with aspects such as age, gender, education, occupation, ethnicity, household size and so on, but it is necessary to rigorously define their content on each marketing study [9]. As described by [10], demographic transformations exercise among the strongest influences on the perspective of consumer markets. Pride and Ferrell [11] demonstrate that demographic factors can significantly influence behavior, both crosswise and dynamically. The influence of demographic factors can be analysed individually or according to their synergy in generating the impact on consumer behavioral patterns based on schemes indicating activities, opinions and interests of individuals [12]. Consumer age, as shown in [13], distinctly influences the functioning of individuals at physiological, social and economic level, putting their mark on preferences about goods and services and, in the broader part, the influence of age on behavior can be combined with other demographic factors such as gender, matrimonial status, number of household members and so on, generating a permanent dynamic in the dimensions and structure of target populations. The demographic analysis presents a high interest because it is associated with the population, and people, as indicated in [14], are those who mainly make up markets and the specifics and changes that occur at their level have major business implications.

The economic world, as observed in [15], is turning into a purchasers' market, where the consumers keep becoming more and more discerning and also being more able than at any other time to choose from the worldwide market. A longing to improve the quality of medical services gives an upper hand in the competitive environment, upholds client satisfaction, 


\section{DOI: $10.17148 /$ IARJSET.2021.8313}

generates long-term commercial relationships and supports the proficiency of available assets usage [16]. As the population keeps evolving and maturing, the requirement for extra medical services is probably going to increment and, in this manner, more facilities might be needed to satisfy the developing needs [17]. In that context, the research on the impact of the patients' age on the healthcare services becomes a necessity [18], supporting the development of successful business.

\section{MATERIALS AND METHODS}

As a component of the marketing endeavours to offer scientific support for the ever-present need for adaptation of healthcare suppliers in Romania, based on the behaviour of the consumers, an extensive statistical survey was implemented. The mentioned quantitative study looked to give significant information about decision-making and the instruments of fulfilment development among the patients, just as the elements that impact it and the ramifications. The examination was led on a number of 385 patients over the age of 18 that had wilfully utilized medical services provided by clinical units situated in Bucharest and the encompassing region of Ilfov, inside a time span of a year. As far as survey participants' structure, the age and gender conveyance of frequencies were similar to those officially communicated by the Government through the National Statistics Institute in regards to the population. Therefore, the gathered information was relevant and did not need any additional correction measures of ponderation for representativity. Addressing the scope of the current paper, the accompanying outcomes are conveying an extent of the referenced survey's content, whose degree was more extensive as far as marketing ramifications in regards to the creation and the utilization of medical care administrations.

\section{RESULTS AND DISCUSSION}

In terms of influences on consumer behavior, the survey's results showed that age significantly influenced the extent to which there is a concern if the made choice was the best, the level of impact from other people's opinions about medical services, the favoured way of action should the need for healthcare re-emerge and the importance given to medics' names in regard to choosing a service provider.

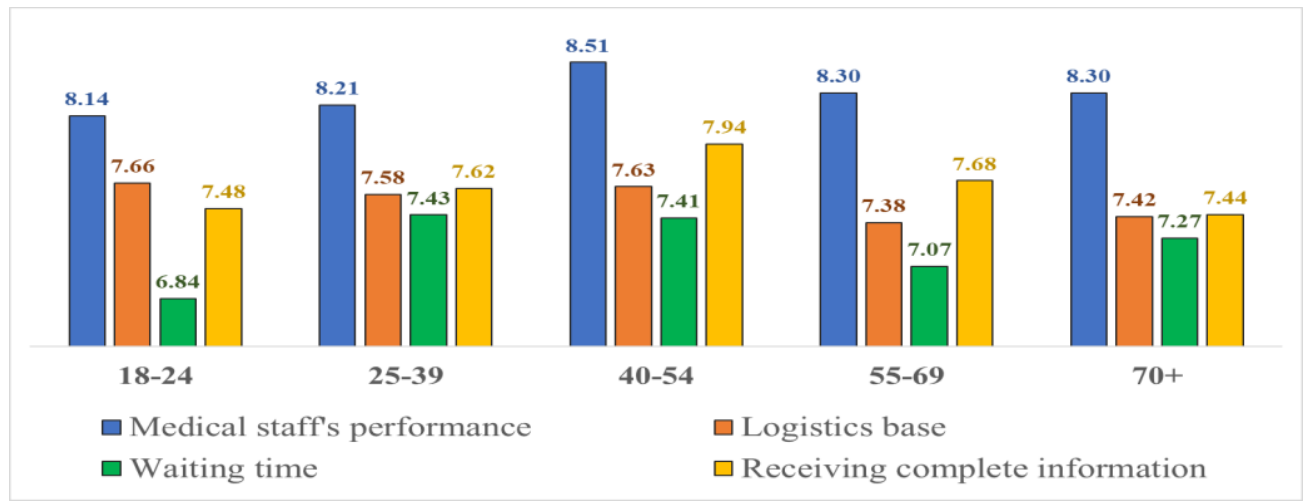

Fig. 1 Age influence on the importance of some quality factors for healthcare services (score out of 10)

Source: Author statistical survey

The results of the study indicated that the performance of the medical staff ranked as highly important for the patients, with a peak for the 40-54 year cohort (average score of 8.51 out of 10), followed by the 55-69 and 70+ year groups (each at 8.30). The logistics base was awarded a relative higher importance by the patients with ages between 18 and 54 years (7.66 for 18-24 year, 7.58 for 25-39 year and 7.63 for 40-54 year groups). The waiting time's importance was valuated especially by the patients between 25 and 54 years ( 7.43 for 25-39 year and 7.41 for $40-54$ year cohorts). The importance of receiving complete information was stronger for the individuals between 25 and 69 years (peaking at 7.94 for the 40 54 year group, followed by the 55-69 year group with 7.68 and the 25-39 year group with 7.62). The influence of age on the importance given by the patients to those factors was confirmed statistically through ANOVA analysis ( $\mathrm{p}=0.013$ for the performance of the medical staff, $\mathrm{p}=0.002$ for the logistics base, $\mathrm{p}=0.045$ for the waiting time, $\mathrm{p}=0.029$ for receiving complete information, unifactorial, $\alpha=0.05$ ). 
DOI: $10.17148 /$ IARJSET.2021.8313

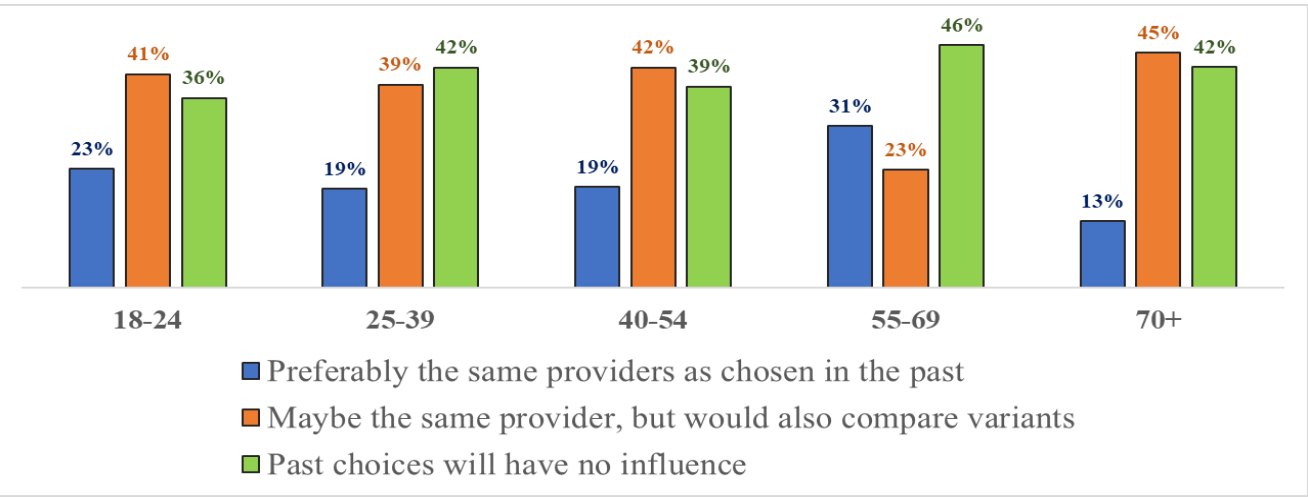

Fig. 2 Age influence on the favoured way of action should the need for healthcare re-emerge

Source: Author statistical survey

Overall, in case of the re-emergence of a need for healthcare, the tendency for the re-activation of a previous choice for a medical services provider is generally the least intense in all age groups excepting the 55-69 year cohort (placing second as in-group proportion, with $31 \%$ ). The existence of a certain preference for choosing the same providers is dominant for the $70+$ year patients ( $45 \%$ of them), $40-54$ year group ( $42 \%$ of it) and $18-24$ year group (a proportion of $41 \%$ ), while placing second for the 25-39 year patients (with an in-group proportion of 39\%). The patients most inclined to make the decision without any influence of the past choices belonged to the 55-69 year group (mounting to an in-group proportion of $46 \%$ ), followed by the 25-39 and 70+ year (each one's proportions being 42\%). Notably, that option also scored high in the preferences of the other groups, namely $39 \%$ of the $40-54$ year patients and $36 \%$ of the $18-24$ year group. The Pearson $\chi^{2}$ testing confirmed the statistical relevance of patient age's influence on the favoured way of action $(\mathrm{p}=0.0004$, $\alpha=0.05)$.

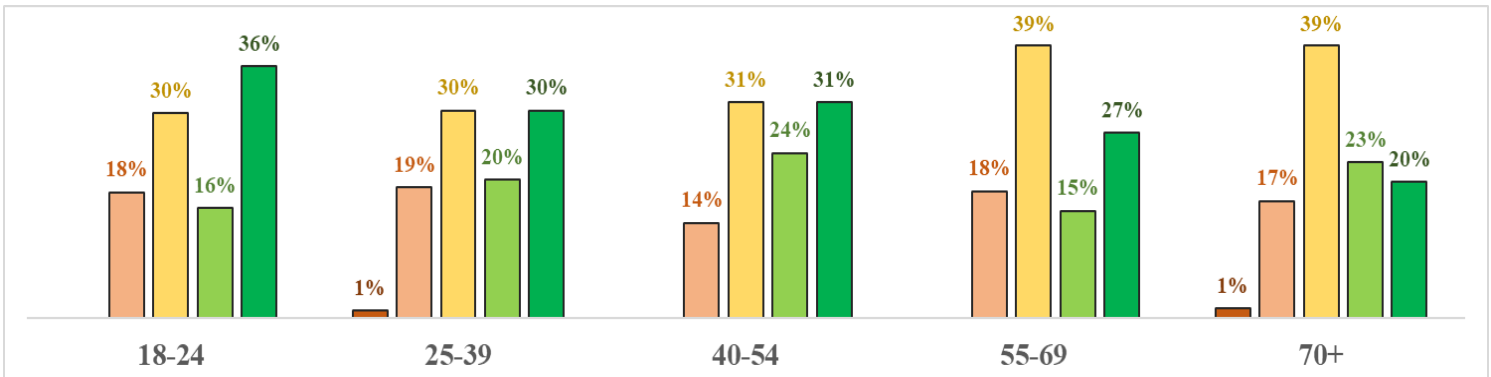

$\square$ Not at all important $\square$ Slightly important $\square$ Moderately important $\square$ Very important $\square$ Extremely important

Fig. 3 Age influence on the importance given to medics' names in regard to choosing a service provider

Source: Author statistical survey

The highest importance given to medics' names when choosing a healthcare provider was prevalent with the younger patients (with a leading proportion of 36\% among the 18-24 year group), also being very significant with 40-54 year and 25-39 year cohorts (with $31 \%$ and $30 \%$ in-group proportions). The medics' identities were awarded with the secondhighest degree of importance especially by the $40-54$ year patients (24\% of them) and by the $70+$ year ones (with a proportion of 23\%). The moderate level was dominant with 55-69 and 70+ year groups (39\% of each), also being wellrepresented with the other groups (30-31\% proportions of each). The names were slightly important for $18-19 \%$ of the patients of each group excepting for the 40-54 year ones (with only $14 \%$ in-group occurrence). The lack of importance, on the other hand, received very few of the options, only 1\% of the 25-39 and 70+ year cohorts. By aggregating the options, the very important and extremely important levels of importance represented a main characteristic of the 40-54 year group (with 55\% in-group proportion), 18-24 year group (52\% of it) and $25-39$ year group (50\% of it). Through ANOVA analysis, the statistical relevance of age's impact on the importance given to medics' names was also confirmed $(\mathrm{p}=0.023$, unifactorial, $\alpha=0.05)$. 


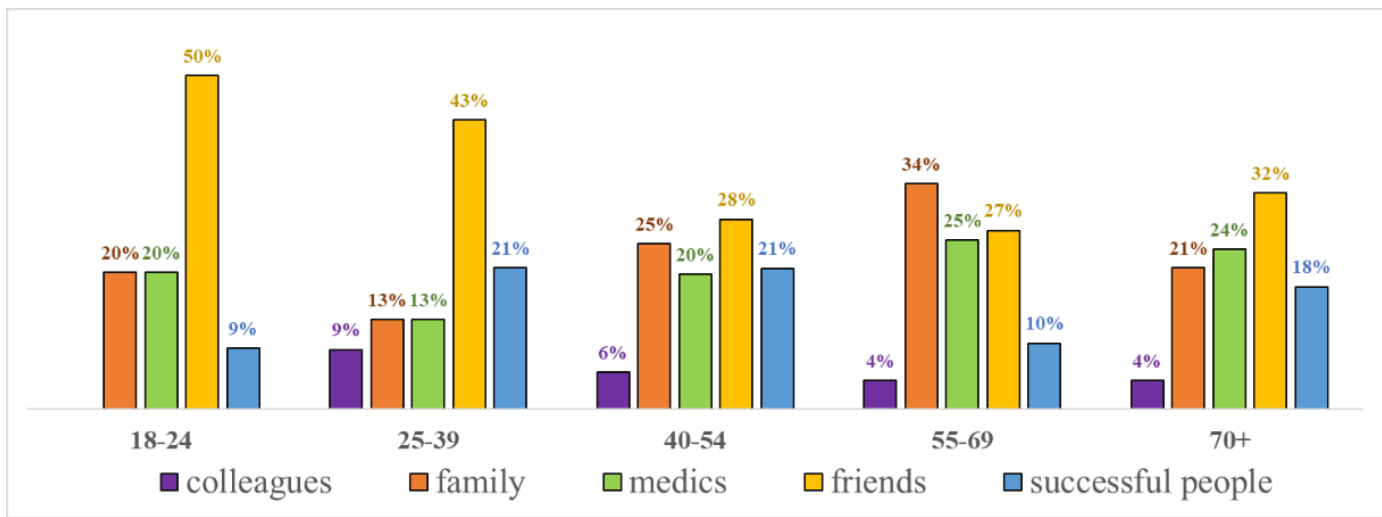

Fig. 4 Age influence on choosing the most important influencers on healthcare topics

Source: Author statistical survey

Regarding the influencers on the healthcare topics for the patients, the friends are the major source, leading the in-group proportions for the 18-24 year cohort (mounting to 50\% of its members mentioning it as the most important influencer), the 25-39 year one (up to $43 \%$ ), $70+$ year (32\% of its cases) and also $40-54$ year ( $28 \%$ of it). The only age group with a different leading source is 40-54 year, where the family got 34\%. The family scored also well in the 40-54 year group (with 25\%), the 70+ year group (with 21\%) and 18-24 group (with a proportion of 20\%). The medics had a relatively stronger influence on the 55-69 year patients (25\% of them indicating the medics as the leading source), the $70+$ year patients (24\% of them), 18-24 and 40-54 year (each with $20 \%$ in-group proportions). Successful people mainly influenced the 25-39 and 30-54 year groups (as indicated by 21\% of each). Patients' colleagues ranked lowest, with a maximum proportion of $9 \%$ in the case of the 25-39 year cohort. The influence of patients' age was statistically confirmed by means of Pearson $\chi^{2}$ testing $(\mathrm{p}=0.045, \alpha=0.05)$.

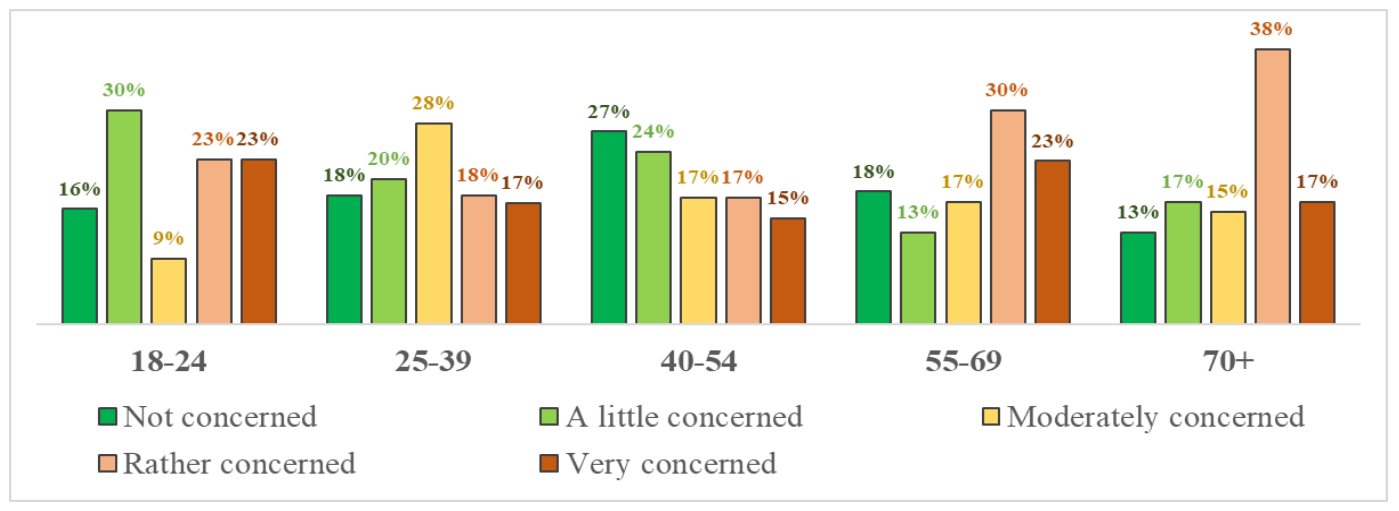

Fig. 5 Age influence on the concern whether the made choice was the best or not

\section{Source: Author statistical survey}

As an expression of the tendency of patients for experiencing cognitive dissonance related to the made decision regarding the medical services provider, the post-consumption concern was most intense in the 18-24 year and 55-69 year groups (with $23 \%$ of each indicating the maximum level). A state of rather concerned was very relevant to the $70+$ cohort (mounting to a proportion of 38\% of its members), also being well-represented in the 55-69 year interval (30\% of it) and $18-24$ year (23\% of it). A moderate intensity was a characteristic of the $25-39$ year group (for $28 \%$ of those patients). As for the rather concerned patients, the 18-24 year cohort proved the most relevant (30\% of it), followed by 40-54 year ( $24 \%$ of the responses from this group) and by 25-39 year (with an in-group frequency of 20\%). In terms of the least intense worrying, the patients belonging to the 40-54 year group were the best represented (with a proportion of $27 \%$ of them). If further aggregated, the study indicated that the most susceptible patients to experience worrying (rather and very concerned) were those aged above average, as indicated by the 70+ year respondents (55\% of them) and the 55-69 year respondents (53\% of them). On the other hand, an aggregate of a little concern and no concern above $50 \%$ was only exhibited by the $40-54$ year cohort (51\% of it), while the 18-24 year cohort followed with a $46 \%$ in-group proportion. 


\section{International Advanced Research Journal in Science, Engineering and Technology}

Vol. 8, Issue 3, March 2021

\section{DOI: $10.17148 /$ IARJSET.2021.8313}

Therefore, the study showed that patients' age significantly influenced the intensity of concern whether the made choice was the best ( $\mathrm{p}=0.039$ resulted from ANOVA analysis, unifactorial, $\alpha=0.05$ ).

\section{CONCLUSION}

This paper presented some of the specific ways that patients' age influences their behavior when facing the need to address a healthcare issue and also the influences on some elements of their decision-making process when choosing a provider of medical services. Because the study demonstrated statistically that age had influence on behavior, the market segmentation based on that factor can provide a solid foundation for creating and maintaining a patient-focused orientation of healthcare. Based on this study's findings, the medical services providers can develop the most suitable strategies in order to attract patients and satisfy them at the highest level, by adapting the activities and the management to the specifics of each target groups, thus providing value for the consumer and supporting the achievement of business success.

\section{REFERENCES}

[1]. D.B. Holt, "How Consumers Consume: A Typology of Consumption Practices", Journal of Consumer Research, vol. 22, pp. 1-16, 1995.

[2]. M. Jagtap and A. Deshmukh, "Consumer Behavior Research: A Literature Review", International Journal of Management Studies, vol. V, is. 4(9), pp. 147-151, 2018.

[3]. D.C. Ahrholdt, S.P. Gudergan and C.M. Ringled, "Enhancing loyalty: When improving consumer satisfaction and delight matters", Journal of Business Research, 93, pp. 18-27, 2019.

[4]. A. Stankevich, "Explaining the Consumer Decision-Making Process: Critical Literature Review", Journal of International Business Research and Marketing, 2(6), pp. 7-14, 2017.

[5]. T. Hansen, "Perspectives on consumer decision making: An integrated approach", Journal of Consumer Behaviour, 4(6), pp. 420-437, 2005.

[6]. F. Kardes, M. Cronley and T. Cline, "Consumer Behavior”. Mason, United States: South-Western Cengage Learning, 2011.

[7]. A. Puška, I. Stojanović, S. Šadić and H. Bečić, "The Influence of Demographic Characteristics of Consumers on Decisions to Purchase Technical Products", The European Journal of Applied Economics, 15(2), pp. 1-16, 2018

[8]. D. Allen, "Customer Satisfaction Research Management. A Comprehensive Guide to Integrating Customer Loyalty and Satisfaction Metrics in the Management of Complex Organizations”. Milwaukee, United States: ASQ Quality Press, 2004.

[9]. R. Wilson and C. Gilligan, "Strategic Marketing Management: Planning, implementation and control", 3rd Ed. Oxford, United Kingdom: Elsevier, 2005.

[10]. Y. Gabriel and T. Lang, "The Unmanageable Consumer", 2nd Ed. London, United Kingdom: SAGE Publications, 2006.

[11]. W. Pride and O. Ferrell, "Foundations of Marketing", 8th Ed. Boston, United States: Cengage, 2019.

[12]. W. Perreault Jr., J. Cannon and J. McCarthy, "Essentials of Marketing. A Marketing Strategy Planning Approach”, 13th. Ed. New York, United States: McGraw-Hill/Irwin, 2012.

[13]. J. Martins, F. Yusuf and D. Swanson, “Consumer Demographics and Behaviour. Markets are People”. Dordrecht, Netherlands: Springer, 2012.

[14]. P. Kotler, G. Armstrong, L. Harris and H. He, "Principles of Marketing”, 8th European Ed. Harlow, United Kingdom: Pearson Education, 2020.

[15]. H. Peck, A. Payne, M. Christopher and M. Clark, "Relationship Marketing: Strategy and implementation". Oxford, United Kingdom: ButterworthHeinemann, 1999.

[16]. M.A. Mosadeghrad, "Healthcare service quality: towards a broad definition”, International Journal of Health Care Quality Assurance, 26(3), pp. 203-219, 2013.

[17]. C.R. McConnell, "Hospitals and health systems: what they are and how they work". Burlington, Unites States: Jones \& Bartlett Learning, 2020.

[18]. C. Gilligan and R. Lowe, "Marketing and Health Care Organizations". Boca Raton, United States: CRC Press, 2016. 